\title{
Actuarial day-by-day survival rates of preterm infants admitted to neonatal intensive care in New South Wales and the Australian Capital Territory
}

\author{
Mohamed E Abdel-Latif, ${ }^{1,2}$ Zsuzsoka Kecskés, ${ }^{1,2}$ Barbara Bajuk 3,4; On behalf of \\ the NSW and the ACT Neonatal Intensive Care Audit Group
}

\begin{abstract}
'Department of Neonatology, Canberra Hospital, Garran, Australian Capital Territory, Australia

${ }^{2}$ Department of Neonatology,

The Clinical School,

The Australian National University Medical School, PO Box 11, Woden, ACT 2006 Australia

${ }^{3}$ Neonatal Intensive Care Units' (NICUs') Data

Collection, NSW Pregnancy and Newborn Services

Network, Westmead, New South Wales, Australia

${ }^{4}$ School of Public Health, University of Sydney, Camperdown, New South Wales, Australia
\end{abstract}

\section{Correspondence to} Associate Professor Mohamed E Abdel-Latif, Department of Neonatology, The Australian National University Medical School, PO Box 11, Woden, ACT 2606, Australia; abdel-latif.mohamed@ act.gov.au

Accepted 30 June 2011

\begin{abstract}
Objective To characterise the actuarial day-by-day survival of premature infants in a geographically defined population.

Setting 10 Neonatal Intensive Care Units (NICUs) in New South Wales (NSW) and Australian Capital Territory (ACT), Australia.

Design Retrospective analysis of prospectively collected data as part of NICUs' data collection in NSW and ACT.

Subjects Premature infants born at $22^{+0}$ to $31^{+6}$ weeks' gestation between January 1997 and December 2006 and admitted to one of the 10 NICUs in NSW and ACT.

Outcome Actuarial day-by-day survival to discharge from NICU.
\end{abstract}

Results Survival to discharge after initiation of neonatal intensive care ranges from $30.0 \%$ at 23 weeks' gestation to $98.8 \%$ at 31 weeks. Actuarial day-by-day survival increased across all gestations. This improvement was most notable among the babies who were born $<26$ weeks gestation.

Conclusion Preterm infants who survive the first few postnatal days have considerable chances of long-term survival. It is important to revise the information stored regarding chances of survival so it covers chances at regular intervals, especially after the first few days of life.

\section{INTRODUCTION}

Establishing data for survival of premature infants by gestational age is important for counselling parents both prenatally and postnatally. ${ }^{12}$ Overall survival to discharge of premature infants, unlike actuarial day-by-day survival, is well studied and has been published for babies in different populations. ${ }^{3}$ Overall, survival is provided as a single survival rate from admission to discharge for each birthweight or gestational age category. ${ }^{24}$ Actuarial survival, on the other hand, is provided as day-by-day survival from the time of admission and is important for consultation with parents of infants during their stay in the Neonatal Intensive Care Unit (NICU). ${ }^{3}$

The purpose of this study was to characterise the actuarial survival to discharge in a large cohort of preterm infants $\left(22^{+0}\right.$ to $31^{+6}$ weeks' gestation) admitted to any of the regional NICUs within the network in New South Wales (NSW) or the Australian Capital Territory (ACT), Australia, between 1997 and 2006. Furthermore, we aimed to examine the effect of sex and increasing postnatal age on predicted survival.

\section{What is already known on this topic}

Overall survival to discharge, unlike actuarial dayby-day survival, for premature infants of different populations is well studied.

\section{What this study adds}

- Among infants $<26$ weeks' gestation admitted to the Neonatal Intensive Care Unit (NICU), day-by-day actuarial survival rate increases during the first few days of life.

- Revising the chances of survival during the early NICU course would improve counselling for parents.

\section{METHODS AND SUBJECTS}

\section{Data source}

Perinatal survival and other outcome data for infants of $22^{+0}$ to $31^{+6}$ weeks' gestation were extracted from the NICUs data collection, which is a population-based, prospectively collected, statewide data collection of neonates admitted to all 10 NICUs (8 perinatal centres and 2 children's hospitals) in NSW and ACT. Data are prospectively collected and organised within each NICU by a designated clinical nurse specialist using standard operational definitions across the network (B Bajuk, $\mathrm{T}$ Vincent, unpublished observation). The data are then compiled into a central database located at the NSW Pregnancy and Newborn Services Network, where rigorous quality control procedures are applied to ensure the accuracy of the data collection. ${ }^{5}$ In Australia, it has been recommended by the National Health and Medical Research Council that "Wherever possible preterm birth at $<33$ weeks should occur in a perinatal centre that has the expertise to care for the woman and her preterm infant." In general, preterm infants $<33$ weeks who are born in non-tertiary hospitals are transferred to tertiary centres by a specialised neonatal and paediatric emergency transport service team. ${ }^{78}$

\section{Definitions}

Chronic lung disease (CLD) is defined as the need for supplementary oxygen and/or ventilatory support at 36 weeks postmenstrual age. ${ }^{9} 10$ Intraventricular haemorrhage (IVH) grading is 
based on Papile classification ${ }^{11}$ and necrotising enterocolitis is staged using the modified Bell Staging Criteria. ${ }^{12}$ Retinopathy of prematurity (ROP) was defined as per the International Classification of ROP with Stage of I-IV assigned to positive cases. $^{13}$

\section{Statistical analysis}

Statistical analyses were performed using the Statistical Package for the Social Sciences (SPSS) software version 15.0 (SPSS, Chicago, Illinois, USA, 2006). Data are presented as number (\%) or median(IOR). The Kaplan-Meier (product-limit) method $^{14}$ was used to estimate actuarial survival. Differences in median survival time (eg, males vs females) were compared using the Mantel-Cox log-rank test. ${ }^{15}$ For actuarial analysis, the event of interest was death and time-to-event was the number of days survived. Infants with no events were considered as right censored observations. Day-by-day postnatal survival rates were calculated as the percentage of survival at specific postnatal days (eg, day 1, first 24 h of life).

\section{4 total births at 22 - 31 weeks' gestation in NSW and the ACT between 1997-2006}

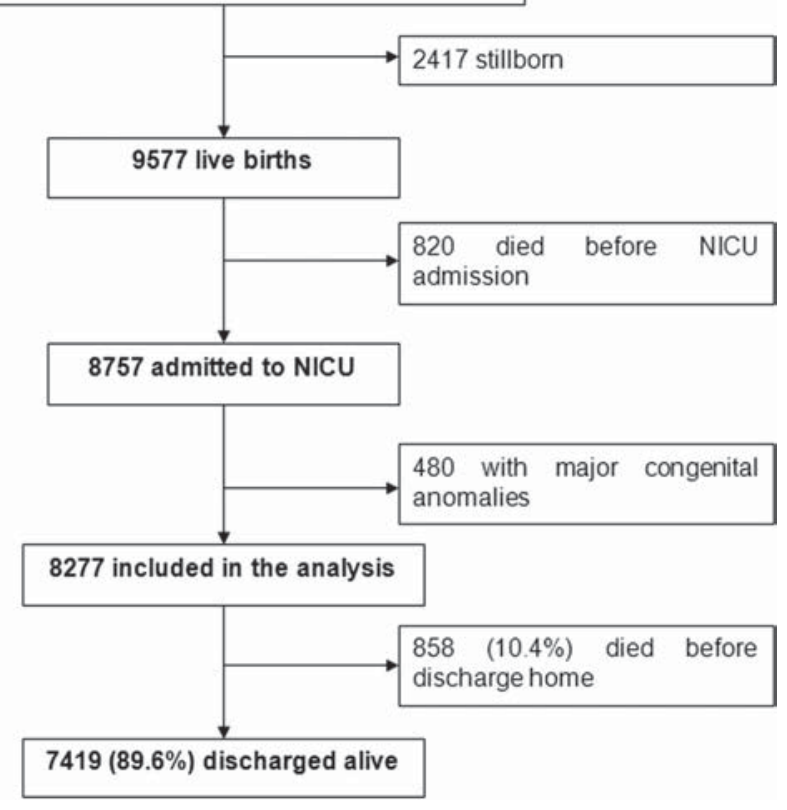

Figure 1 Profile of babies born at 22-31 weeks' gestation from admission to discharge/death.
Actuarial survival to a given day was graphed by gestational age and stratified by sex. All analyses were prespecified. The level of statistical significance for all analyses was set at $\mathrm{p}<0.05$, using two-tailed comparisons.

\section{RESULTS}

The study group's profile from birth to discharge/death is shown in figure 1 . There were 8757 infants admitted to the 10 collaborating NICUs between January 1997 and December 2006. Stillbirths $(n=2417)$, death before NICU admission $(n=820)$ and infants with congenital abnormalities $(n=480)$ were excluded from this study. The remaining 8277 patients were included in the final analysis. Overall, 858 (10.4\%) of the infants admitted died before NICU discharge.

\section{Antenatal and perinatal characteristics}

The antenatal and perinatal characteristics and major neonatal morbidities observed among the study group are shown in tables 1 and 2. The median (IOR) gestational age of the study group was 29.0 (27.0-30.0) weeks with a birth weight (IOR) of 1235.0 (940.0-1520.0) g. Antenatal steroid administration was completed in $88.2 \%$ of the group. CLD was present in $15.4 \%$ of the patients, and $7.1 \%$ of the patients required home oxygen. IVH grade 3-4 was found in $6.0 \%$ of the patients and ROP grade 3-4 was found in $5.5 \%$ of the patients.

\section{Survival to discharge and time of death}

Survival to discharge and time of death are shown in figure 2. Survival increased from $0 \%$ at 22 weeks' gestation to $98.8 \%$ at 31 weeks. Female infants had better chances of survival than male infants especially among infants $<27$ weeks' gestation (figure 2).

The majority of deaths occurred in the first few days of life, particularly in the most premature patients (table 3). Overall, $32.6 \%, 10.9 \%$ and $9.6 \%$ of the deaths occurred on days 1,2 and 3 of life, respectively.

The median (IOR) age at time of death ranged from 1.0 (1.0-3.5) day at 22 weeks' gestation to 8.0 (2.0-18.0) days at 30 weeks' gestation, with an overall median (IOR) age of death of 3.0 (1.0-11.0) days (table 2). The median time of death was not different between males and females (table 2). However, there was a trend for earlier death in male infants (figure 2).

\section{Actuarial survival}

Day-by-day actuarial survival to discharge, stratified by sex, is shown in figure 3 . The graphs were truncated at day 60 of

Table 1 Maternal characteristics of the study group

\begin{tabular}{lcccr}
\hline Characteristic/morbidity & Overall $(\mathbf{n}=\mathbf{8 2 7 7})$ & Males $(\mathbf{n}=\mathbf{4 5 2 3})$ & Females $(\mathbf{n}=\mathbf{3 7 5 4})$ & p Value \\
\hline Maternal age (years) & $30.0(25.0-34.0)$ & $30.0(25.0-34.0)$ & $30.0(25.0-34.0)$ & 0.186 \\
Aboriginal ethnicity & $427(5.2)$ & $238(5.3)$ & $189(5.0)$ & 0.573 \\
Assisted conception & $1112(13.4)$ & $590(13.0)$ & $522(13.9)$ & 0.244 \\
Multiple pregnancy & $2393(28.9)$ & $1250(27.6)$ & $1143(30.4)$ & 0.005 \\
Pregnancy induced hypertension & $1494(18.4)$ & $709(16.1)$ & $785(21.3)$ & $<0.001$ \\
Rupture of membranes $>24 \mathrm{~h}$ & $2059(24.9)$ & $1128(24.9)$ & $931(24.8)$ & 0.937 \\
Antepartum haemorrhage & $2063(25.5)$ & $1190(27.0)$ & $873(23.6)$ & $<0.001$ \\
Intrauterine growth restriction & $815(10.1)$ & $361(8.2)$ & $454(12.3)$ & $<0.001$ \\
Fetal distress & $1428(17.3)$ & $743(16.4)$ & $685(18.2)$ & 0.033 \\
Antenatal steroids completed & $7301(88.2)$ & $3959(87.5)$ & $3342(89.0)$ & 0.038 \\
Vaginal breech delivery & $641(7.9)$ & $351(8.0)$ & $290(7.9)$ & 0.899 \\
Emergency caesarean section & $1709(21.1)$ & $978(22.2)$ & $731(19.8)$ & 0.008 \\
\hline
\end{tabular}

Data are presented as median (IOR) or $\mathrm{n}(\%)$. 
Table 2 Perinatal characteristics and major neonatal morbidities of the study group

\begin{tabular}{|c|c|c|c|c|}
\hline Characteristic/morbidity & Overall $(n=8277)$ & Males $(n=4523)$ & Females $(n=3754)$ & p Value \\
\hline Born in non-tertiary hospital & $801(9.7)$ & $465(10.3)$ & $336(9.0)$ & 0.051 \\
\hline Gestational age (weeks) & $29.0(27.0-30.0)$ & $29.0(27.0-30.0)$ & $29.0(27.0-30.0)$ & 0.241 \\
\hline Birth weight $(\mathrm{g})$ & $1235(940-1520)$ & $1280(975-1560)$ & $1180(900-1460)$ & $<0.001$ \\
\hline Birth weight $<10$ th percentile & $773(9.3)$ & $393(8.8)$ & $375(10.0)$ & 0.067 \\
\hline Head circumference $<10$ th percentile & $574(7.6)$ & $203(4.9)$ & $371(10.8)$ & $<0.001$ \\
\hline Apgar score $<7$ at $5 \mathrm{~min}$ & $1334(16.2)$ & $780(17.4)$ & $554(14.8)$ & 0.002 \\
\hline Surfactant & $4132(49.9)$ & $2337(51.7)$ & $1759(47.8)$ & $<0.001$ \\
\hline Air leak requiring drainage & $345(4.2)$ & $193(4.3)$ & $152(4.0)$ & 0.532 \\
\hline Postnatal steroids & $879(10.6)$ & $514(11.4)$ & $365(9.7)$ & 0.014 \\
\hline CLD & $1276(15.4)$ & $744(16.4)$ & $532(14.2)$ & 0.006 \\
\hline Home oxygen & $572(7.1)$ & $343(7.8)$ & $229(6.2)$ & 0.005 \\
\hline PDA treated with indomethacin/surgery & $1960(23.7)$ & $1046(23.1)$ & $914(24.3)$ & 0.210 \\
\hline NEC & $457(5.5)$ & $258(5.7)$ & $199(5.3)$ & 0.456 \\
\hline Any major surgery & $416(5.0)$ & $242(5.4)$ & $174(4.6)$ & 0.108 \\
\hline IVH grade 3 or $4^{*}$ & $467 / 7810(6.0)$ & $280 / 4191(6.7)$ & $187 / 3490(5.3)$ & 0.012 \\
\hline ROP grade 3 or $4^{*}$ & $345 / 6260(5.5)$ & $192 / 3382(5.7)$ & $153 / 2878(5.3)$ & 0.525 \\
\hline Proven systemic infection & $1775(21.4)$ & $1004(22.2)$ & $771(20.5)$ & 0.064 \\
\hline Hospital mortality & $858(10.4)$ & $506(11.2)$ & $352(9.4)$ & 0.008 \\
\hline Gestational age at death (weeks) & $26.4(25.0-29.0)$ & $26.4(25.0-29.0)$ & $26.4(25.0-29.0)$ & 0.863 \\
\hline Age at death (days) & $3.0(1.0-11.0)$ & $3.0(1.0-11.0)$ & $3.0(1.0-11.0)$ & 0.458 \\
\hline Age at discharge (days) ${ }^{\dagger}$ & $56.0(42.0-76.0)$ & $55.0(41.0-75.0)$ & $56.0(42.0-76.0)$ & 0.111 \\
\hline Gestation at discharge (weeks) ${ }^{\dagger}$ & $37.1(36.0-38.7)$ & $37.1(36.0-38.7)$ & $37.1(36.0-38.6)$ & 0.645 \\
\hline
\end{tabular}

Data are presented as median (IQR) or $\mathrm{n}(\%)$.

CLD is defined as requiring respiratory support at 36 weeks of gestation.

*Denominator is number of infants examined.

${ }^{\dagger}$ Calculated for infants who were discharged alive.

CLD, chronic lung disease; IVH, intraventricular haemorrhage; NEC, necrotising enterocolitis; PDA, patent ductus arteriosus; ROP, retinopathy of prematurity.

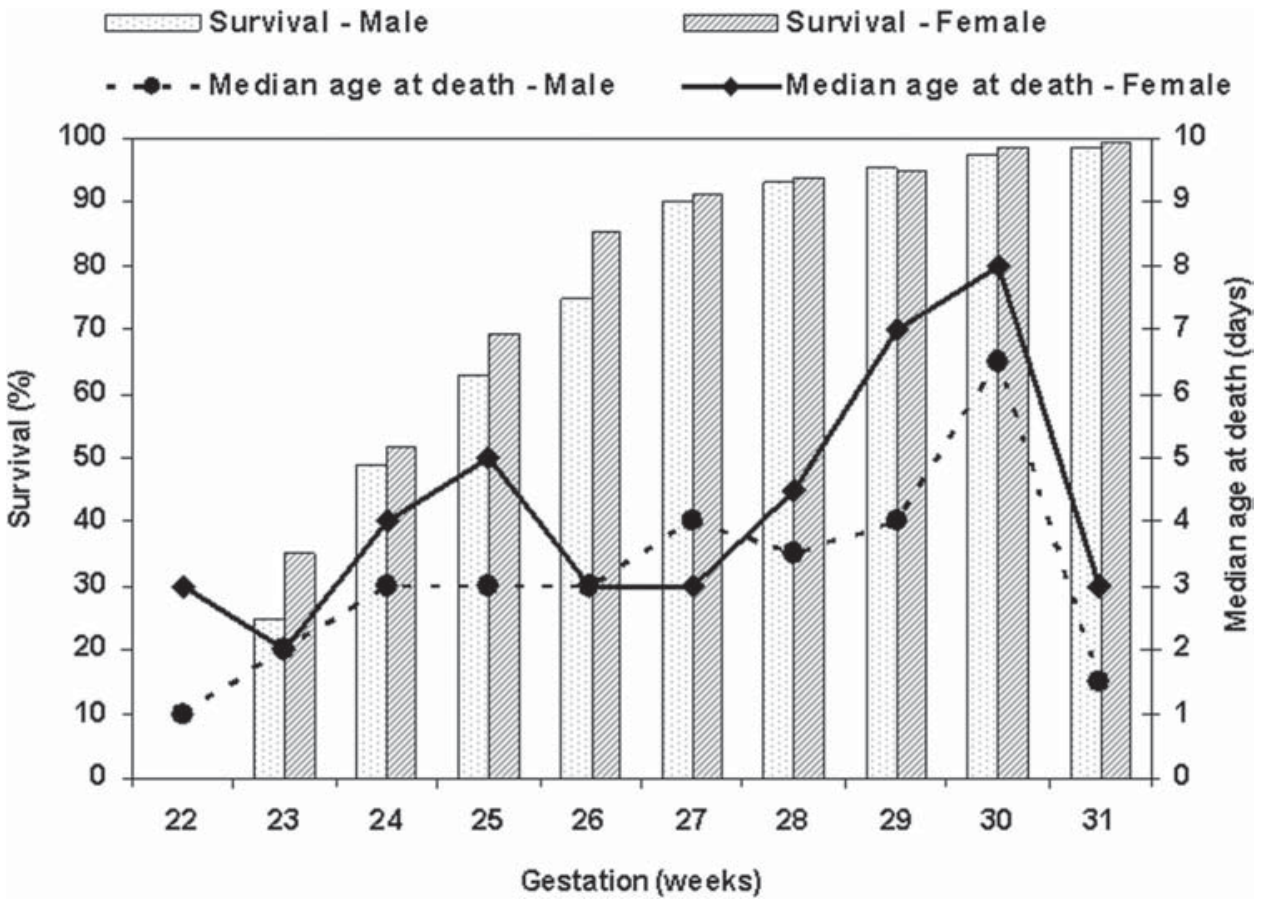

Figure 2 Gestational age specific survival to discharge and median age at death in preterm infants born between 1997 and 2006 and admitted to a neonatal intensive are unit.

life, as survival remained mostly unchanged after this period. The slope of the curves shows that the risk of death is highest within the first few days of life and for the most severely premature patients. Overall risk of death was also higher for male infants than for female infants $(\mathrm{p}=0.008)$.

\section{Survival rates}

Day-by-day survival rates for the first week of life stratified by sex are shown in table 3. Chances of survival improve day-byday across all gestations. This improvement was most notable among the babies who were born $<26$ weeks gestation. For 
Table 3 Day-by-day survival rate to discharge recalculated at fixed intervals on the surviving cohort and stratified by gestation among male and female infants 22-31 weeks' gestation born between 1997 and 2006 and admitted to a neonatal intensive care unit

\begin{tabular}{|c|c|c|c|c|c|c|c|c|c|c|}
\hline \multirow[b]{2}{*}{ Gestation (weeks) } & \multirow[b]{2}{*}{ Total admitted } & \multirow[b]{2}{*}{ Total survived } & \multicolumn{8}{|c|}{ Day-by-day survival (\%) } \\
\hline & & & Day 1 & Day 2 & Day 3 & Day 4 & Day 5 & Day 6 & Day 7 & Overall \\
\hline \multicolumn{11}{|l|}{ Male infants } \\
\hline 22 & 6 & 0 & 16.7 & 0.0 & - & - & - & - & - & 0 \\
\hline 23 & 60 & 15 & 63.3 & 92.1 & 88.6 & 93.5 & 96.6 & 89.3 & 96.0 & 25 \\
\hline 24 & 211 & 103 & 83.4 & 93.8 & 93.3 & 96.1 & 96.6 & 97.9 & 99.3 & 48.8 \\
\hline 25 & 270 & 169 & 85.9 & 96.1 & 93.7 & 99.5 & 98.6 & 98.5 & 99.0 & 62.6 \\
\hline 26 & 388 & 290 & 93.3 & 96.1 & 95.7 & 99.7 & 99.7 & 99.4 & 98.5 & 74.7 \\
\hline 27 & 421 & 380 & 97.6 & 98.8 & 99.5 & 99.0 & 99.8 & 99.5 & 99.5 & 90.3 \\
\hline 28 & 562 & 524 & 97.5 & 99.3 & 99.8 & 99.6 & 99.6 & 99.8 & 99.6 & 93.2 \\
\hline 29 & 643 & 612 & 98.4 & 99.5 & 99.7 & 99.5 & 99.4 & 99.8 & 99.8 & 95.2 \\
\hline 30 & 881 & 859 & 99.4 & 99.7 & 99.8 & 99.9 & 99.8 & 99.8 & 99.9 & 97.5 \\
\hline 31 & 1081 & 1065 & 99.3 & 99.9 & 99.8 & 99.9 & 99.9 & 99.9 & 100.0 & 98.5 \\
\hline Overall (22-31) & 4523 & 4017 & 96.2 & 98.8 & 98.8 & 99.5 & 99.6 & 99.7 & 99.7 & 88.8 \\
\hline \multicolumn{11}{|l|}{ Female infants } \\
\hline 22 & 2 & 0 & 50.0 & 0.0 & - & - & - & - & - & 0 \\
\hline 23 & 60 & 21 & 72.6 & 90.7 & 91.1 & 98.2 & 94.9 & 98.2 & 98.3 & 35.0 \\
\hline 24 & 172 & 89 & 85.5 & 94.6 & 97.0 & 96.4 & 99.4 & 97.7 & 97.6 & 51.7 \\
\hline 25 & 239 & 166 & 91.6 & 96.3 & 97.0 & 99.6 & 98.3 & 97.4 & 98.3 & 69.5 \\
\hline 26 & 340 & 290 & 94.7 & 98.1 & 99.1 & 99.7 & 99.4 & 99.7 & 99.7 & 85.3 \\
\hline 27 & 360 & 328 & 97.8 & 98.0 & 98.0 & 98.9 & 99.4 & 99.7 & 99.7 & 91.1 \\
\hline 28 & 458 & 430 & 99.8 & 99.8 & 99.6 & 99.6 & 99.8 & 99.6 & 99.3 & 93.9 \\
\hline 29 & 550 & 522 & 98.9 & 99.6 & 99.6 & 99.8 & 99.8 & 99.8 & 99.6 & 94.9 \\
\hline 30 & 689 & 680 & 99.9 & 99.7 & 99.9 & 99.9 & 99.9 & 100.0 & 99.9 & 98.7 \\
\hline 31 & 884 & 876 & 99.7 & 99.9 & 99.9 & 99.9 & 99.8 & 100.0 & 100.0 & 99.1 \\
\hline Overall (22-31) & 3754 & 3402 & 97.1 & 98.9 & 99.1 & 99.5 & 99.7 & 99.6 & 99.4 & 90.6 \\
\hline
\end{tabular}
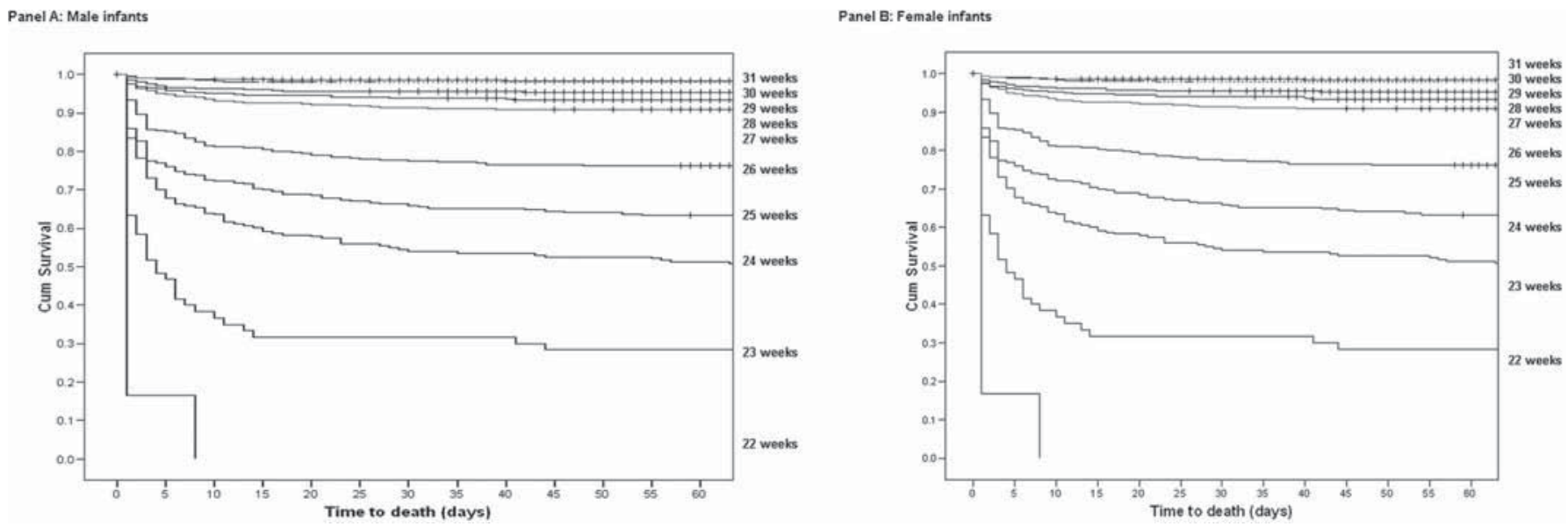

Figure 3 Day-by-day actuarial survival rate to discharge (Kaplan-Meier method) recalculated at daily intervals on the surviving cohort and stratified by gestation among (A) male and (B) female infants 22-31 weeks' gestation born between 1997 and 2006 and admitted to a neonatal intensive care unit. Graphs are truncated at day 60 of life.

example, the survival of males of 24 weeks' gestation improved from $83.4 \%$ on day 1 , to $96.1 \%$ by day 4 , to $99.3 \%$ for those who survived to day 7 . The survival rates were calculated only for the first week of life, because survival remained mostly unchanged after this period.

\section{DISCUSSION}

These data show that the chance of survival of premature infants improves during the first few days of life, which emphasises the importance of revising the chance of survival at regular intervals, especially after the first days of life. This improvement was most notable among the babies who were born most prematurely. Similar observations have been made by other authors. ${ }^{316-18}$

Survival rates of our study group seem to be more favourable. $^{3} 1617$ 19-21 This might be attributed to the larger size of NICUs, higher degree of specialisation of both medical and nursing staff and greater degree of centralisation, preventing dilution of resources and clinical commitment in NSW and ACT.19 21-26 Furthermore, and in contrast to other networks, the NSW/ACT system acts regionally to direct perinatal traffic in order to buffer any individual unit from excessive workloads. In many ways, the system functions as one large amalgamated service network. ${ }^{27}$ Furthermore, our data are more recent 
than those collected previously. In addition, lack of information on stillborn and delivery room deaths may overestimate survival probabilities in our cohort compared with others. Nevertheless, the association between differences in comparative international outcomes and particular organisational characteristics of health services must be inferred only with caution, as highlighted by others. ${ }^{19} 28$

Similar to other studies, the majority of deaths in our setting occurred in the first few days of life, particularly among the most premature babies. ${ }^{17} 182930$

We stratified the day-by-day actuarial survival rate (figure 3 and table 3 ) by sex as male infants had lower survival rate compared with female infants. Similar findings have been reported elsewhere. ${ }^{31-33}$

The strength of our study is that it is based on a large, geographically defined cohort. Such an analysis has the potential to remove the selection bias in hospital-based studies and provides a more accurate picture of neonatal outcome. ${ }^{34} 35$ Furthermore, our study included more recent data on infants who were born more prematurely, compared with previous studies. One important limitation of our data is the lack of detailed information on stillborn, delivery room deaths, and non-initiation and withdrawal of intensive care. Use of our data on deaths after NICU admission for antenatal counselling may overestimate survival probabilities.

In conclusion, our data characterised the actuarial day-byday survival for preterm infants from a geographically defined area. Our data show that preterm infants who survive the first few postnatal days have considerable chance of survival until discharge. These data may be used to counsel parents of preterm infants admitted to NICUs.

Acknowledgements The authors thank the Directors, the NICUs' members and the audit officers of all tertiary units in supporting this collaborative study: NICUs, Dr Jennifer Bowen (Chairperson), Barbara Bajuk (Coordinator), Trina Vincent (Research Officer); Canberra Hospital, A/Prof Zsuzsoka Kecskés (Director), A/Prof Alison Kent, John Edwards; John Hunter Children's Hospital, Dr Chris Wake (Director), Lynne Cruden; Royal Prince Alfred Hospital, A/Prof Nick Evans (Director), Dr Phil Beeby, A/Prof David Osborn, Shelley Reid; Liverpool Hospital, Dr Robert Guaran (Director), Dr lan Callander, Kathryn Medlin, Sara Wilson; Nepean Hospital, Dr Lyn Downe (Director), Mee Fong Chin; The Children's Hospital at Westmead, Prof Nadia Badawi (Director), Robert Halliday, Caroline Karskens; Royal North Shore Hospital, Dr Mary Paradisis (Acting Director), A/Prof Martin Kluckow, Sara Sedgley; Sydney Children's Hospital, Dr Andrew Numa (Director), Dr Gary Williams, Janelle Young; Westmead Hospital, Dr Mark Tracy (Acting Director), Jane Baird; and Royal Hospital for Women, A/Prof Kei Lui (Director), Dr Julee Oei, Diane Cameron. We also thank the babies and their families, the nursing and midwifery, obstetric, and medical records staff of the obstetric and children's hospitals in NSW and the ACT. The authors acknowledge the helpful comments of Dr Koert A de Waal (John Hunter Hospital) on draft of this paper.

Competing interests None.

Ethics approval This study was conducted with the approval granted by the ACT Health Human Research Ethics Committee (No ETH.11/09.1033).

Provenance and peer review Not commissioned; externally peer reviewed.

\section{REFERENCES}

1. Koh T. Simplified way of counselling parents about outcome of extremely premature babies. Lancet 1996;348:963.

2. Bolisetty S, Bajuk B, Abdel-Latif ME, et al. Preterm outcome table (POT): a simple tool to aid counselling parents of very preterm infants. Aust N Z J Obstet Gynaecol 2006;46:189-92.

3. Cooper TR, Berseth CL, Adams JM, et al. Actuarial survival in the premature infant less than 30 weeks' gestation. Pediatrics 1998;101:975-8.

4. Hack M, Horbar JD, Malloy MH, et al. Very low birth weight outcomes of the National Institute of Child Health and Human Development Neonatal Network. Pediatrics 1991;87:587-97.

5. Bajuk B. Validation of the neonatal intensive care units' data collection. Proceedings of the 5th Annual Congress of the Perinatal Society of Australia and New Zealand, 14-18 March 2001, Canberra, ACT, Australia.
6. National Health and Medical Research Council. Clinical Practice Guidelines: Care Around Preterm Birth. Canberra, ACT: National Health and Medical Research Council, 1997.

7. Rashid A, Bhuta T, Berry A. A regionalised transport service, the way ahead? Arch Dis Child 1999:80:488-92.

8. Abdel-Latif ME, Berry A. Analysis of the retrieval times of a centralised transport service, New South Wales, Australia. Arch Dis Child 2009;94:282-6.

9. Shennan AT, Dunn MS, Ohlsson A, et al. Abnormal pulmonary outcomes in premature infants: prediction from oxygen requirement in the neonatal period. Pediatrics 1988:82:527-32.

10. Jobe AH, Bancalari E. Bronchopulmonary dysplasia. Am J Respir Crit Care Med 2001;163:1723-9.

11. Papile LA, Burstein J, Burstein R, et al. Incidence and evolution of subependymal and intraventricular hemorrhage: a study of infants with birth weights less than 1,500 gm. J Pediatr 1978;92:529-34.

12. Bell MJ, Ternberg JL, Feigin RD, et al. Neonatal necrotizing enterocolitis. Therapeutic decisions based upon clinical staging. Ann Surg 1978;187:1-7.

13. Flynn JT. An international classification of retinopathy of prematurity: clinical experience. Trans Am Ophthalmol Soc 1984;82:218-38.

14. Kaplan E, Meier P. Non-parametric estimation from incomplete observations. J Am Stat Assoc 1958;53:457-81.

15. Mantel N. Evaluation of survival data and two new rank order statistics arising in its consideration. Cancer Chemother Rep 1966;50:163-70.

16. Jones HP, Karuri S, Cronin CM, et al. Actuarial survival of a large Canadian cohort of preterm infants. BMC Pediatr 2005;9:40. http://www.biomedcentral. com/1471-2431/5/40 (accessed 21 Jul 2011).

17. Mohamed MA, Nada A, Aly H. Day-by-day postnatal survival in very low birth weight infants. Pediatrics 2010;126:e360-6.

18. Meadow W, Reimshisel T, Lantos J. Birth weight-specific mortality for extremely low birth weight infants vanishes by four days of life: epidemiology and ethics in the neonatal intensive care unit. Pediatrics 1996:97:636-43.

19. Draper ES, Zeitlin J, Fenton AC, et al. Investigating the variations in survival rates for very preterm infants in 10 European regions: the MOSAIC birth cohort. Arch Dis Child Fetal Neonatal Ed 2009;94:F158-63.

20. Field DJ, Dorling JS, Manktelow BN, et al. Survival of extremely premature babies in a geographically defined population: prospective cohort study of 1994-9 compared with 2000-5. BMJ 2008;336:1221-3.

21. Risk adjusted and population based studies of outcome for high risk infants in Scotland and Australia. International Neonatal Network and Scottish Consultant's and Nurses Collaborative Study Group. Arch Dis Child Fetal Neonatal Ed 2000;82:F118-23

22. Australian Health Ministers' Advisory Council, Superspecialty Services Subcommittee. Guidelines for Level Three Neonatal Intensive Care. Canberra, ACT: Australian Institute of Health, 1991.

23. British Association of Perinatal Medicine. Standards for Hospitals Providing Neonatal Intensive Care. London: BAPM, 1996

24. Callaghan LA, Cartwright DW, O'Rourke P, et al. Infant to staff ratios and risk of mortality in very low birthweight infants. Arch Dis Child Fetal Neonatal Ed 2003;88:F94-7.

25. Measuring neonatal nursing workload. Northern Neonatal Network. Arch Dis Child 1993:68:539-43.

26. Pearson G, Shann F, Barry P, et al. Should paediatric intensive care be centralised? Trent versus Victoria. Lancet 1997;349:1213-17.

27. Lui K, Abdel-Latif ME, Allgood CL, et al. Improved outcomes of extremely premature outborn infants: effects of strategic changes in perinatal and retrieval services. Pediatrics 2006:118:2076-83.

28. Parry GJ, Gould CR, McCabe CJ, et al. Annual league tables of mortality in neonatal intensive care units: Iongitudinal study. International Neonatal Network and the Scottish Neonatal Consultants and Nurses Collaborative Study Group. BMJ 1998;316:1931-5.

29. Elder DE, Wong A, Zuccollo JM. Risk factors for and timing of death of extremely preterm infants. Aust N Z J Obstet Gynaecol 2009;49:407-10.

30. Nakhla T, Imaizumi S, Saslow J, et al. The time to death for extremely low birth weight infants in the neonatal intensive care unit. Internet J Pediatr Neonatol 2007;6. http://www.ispub.com/journal/the internet journal of pediatrics and neonatology/volume_6_number_2_15/article/the_time_to_death_for_extremely low birth weight infants in the neonatal intensive care unit.html laccessed 11 May 2011).

31. Bacak SJ, Baptiste-Roberts K, Amon E, et al. Risk factors for neonatal mortality among extremely-low-birth-weight infants. Am J Obstet Gynecol 2005;192:862-7.

32. Itabashi K, Horiuchi T, Kusuda S, et al. Mortality rates for extremely low birth weight infants born in Japan in 2005. Pediatrics 2009;123:445-50.

33. Ingermarsson I. Gender aspects of preterm birth. BJOG 2003;110(Suppl 20):34-8.

34. Potential selection bias in hospital-based studies of perinatal outcome. Paediatr Perinat Epidemiol 2004;18:153.

35. Sackett DL. Bias in analytic research. J Chronic Dis 1979;32:51-63. 


\section{FN}

\section{Actuarial day-by-day survival rates of preterm infants admitted to neonatal intensive care in New South Wales and the Australian Capital Territory}

Mohamed E Abdel-Latif, Zsuzsoka Kecskés and Barbara Bajuk

Arch Dis Child Fetal Neonatal Ed published online August 9, 2011

doi: 10.1136/adc.2011.210856

Updated information and services can be found at:

http://fn.bmj.com/content/early/2011/08/09/adc.2011.210856.full.html

These include:

References This article cites 28 articles, 14 of which can be accessed free at: http://fn.bmj.com/content/early/2011/08/09/adc.2011.210856.full.html\#ref-list-1

$\mathbf{P}<\mathbf{P} \quad$ Published online August 9, 2011 in advance of the print journal.

Email alerting Receive free email alerts when new articles cite this article. Sign up in service the box at the top right corner of the online article.

Advance online articles have been peer reviewed, accepted for publication, edited and typeset, but have not not yet appeared in the paper journal. Advance online articles are citable and establish publication priority; they are indexed by PubMed from initial publication. Citations to Advance online articles must include the digital object identifier (DOIs) and date of initial publication.

To request permissions go to:

http://group.bmj.com/group/rights-licensing/permissions

To order reprints go to:

http://journals.bmj.com/cgi/reprintform

To subscribe to BMJ go to:

http://group.bmj.com/subscribe/ 


\section{Notes}

Advance online articles have been peer reviewed, accepted for publication, edited and typeset, but have not not yet appeared in the paper journal. Advance online articles are citable and establish publication priority; they are indexed by PubMed from initial publication. Citations to Advance online articles must include the digital object identifier (DOIs) and date of initial publication.

To request permissions go to:

http://group.bmj.com/group/rights-licensing/permissions

To order reprints go to:

http://journals.bmj.com/cgi/reprintform

To subscribe to BMJ go to:

http://group.bmj.com/subscribe/ 